Title Page

\title{
Understanding the economic effects of abnormal weather to mitigate the risk of business failures
}

Prof. Dr. Jean-Louis Bertrand ESSCA School of Management

Corresponding author

1 rue Joseph Lakanal

BP 40348

F-49003 ANGERS CEDEX 01

e-mail: jean-louis.bertrand@essca.fr

tel: 33241735743

fax: 33241734748

Prof. Dr. Miia Parnaudeau

ESSCA School of Management

1 rue Joseph Lakanal

BP 40348

F-49003 ANGERS CEDEX 01

e-mail: miia.parnaudeau@essca.fr

tel: 33241734747

fax: 33241734748

Keywords: Weather Risk; Adaptation; Business failure; Resilience 


\title{
Understanding the economic effects of abnormal weather to mitigate the risk of business failures
}

\author{
Blinded Manuscript ${ }^{1}$
}

\begin{abstract}
Warm or cold, wet or dry, weather impacts almost every industry as $70 \%$ of businesses are exposed to unexpected variations that influence demand for goods and services. The financial losses caused by adverse weather that did not seem material enough to have an impact or to require being managed a decade ago, may now do so as the frequency and severity of abnormal weather have dramatically increased. A surge in investigating the contribution of weather to financial distress is also prompted by more reliable weather data, and the development of new risk mitigation tools. Drawing upon the UK's retail sectors for empirical evidence, this paper provides a methodology to determine the contribution of weather to sales and to structure financial products to reduce the consequences of adverse weather on expected cash-flows. Our results open new research opportunities for weather to be considered as an additional cause of business failure.
\end{abstract}

Keywords: Weather Risk, Adaptation, Business failure, Resilience

\section{Introduction}

A drop in sales and earnings may, at some point, reduce the ability of a business to meet its financial obligations, and create a state of financial distress, 
which is the step preceding business failure and reorganization (Gordon, 1971; Stiglitz, 1972). Most failures involve some interaction between external forces in the environment of the company, and the choices made by management to respond to them (Moulton et al., 1996). In particular, the weather is an external factor of growing importance and consequence. Over the last two decades, as a result of climate change, the frequency and intensity of abnormal weather patterns and extreme weather events have significantly increased (WMO, 2013; IPCC, 2014). Today, weather risks, over which managers have no control, affect approximately $70 \%$ of companies worldwide (Hanley, 1999; Dutton, 2002; Larsen, 2006). Abnormal weather events act as environmental jolts (Amankwah-Amoah et al., 2016) that disrupt the financial performance of companies operating in retail, consumer goods, apparel, transportation, utilities, food processing to name a few (Lazo et al., 2011). In a more volatile environment, companies are more likely to exit the market, and the greater the uncertainty, the higher the exit rate (Anderson and Tushman, 2001).

The unusually warm winter temperatures across Europe in 2015-2016 illustrate the extent to which these weather-induced environmental jolts result in reduced consumer spending and lower sales of many consumer goods. Apparel sales were particularly affected (Gustafson, 2016), as these abnormal temperatures delayed the launching of the spring season at H\&M (Milne, 2016), and triggered store closures and job cuts elsewhere (Swamynathan and Layne, 2016).

The repetition and accumulation of the effects of adverse weather events may prove especially harmful to retail companies, as they are particularly exposed to the vagaries of the weather, and display some of the highest failure 
rates (Everett and Watson, 1998; Amankwah-Amoah and Zhang, 2015). For example, Vivarte, the French fashion retailer, which reorganized its debt in 2013 because of lower sales caused by economic conditions made worse by adverse weather, was forced to again reset its financial expectations in the middle of 2016, mostly because of adverse weather in fall and spring. At the same time, competitor IKKS's debt was lowered further by S\&P Global Ratings due to similar reasons (Ruckin, 2013; Fishta and Casiraghi, 2016). In 2014, Jardiland, the leading retailer of garden and pet products initially cut $20,8 \%$ of its workforce and avoided bankruptcy only by being recapitalized by a private equity fund, L-GAM Investments, after it experienced lower sales brought on by two consecutive abnormally cold and wet springs (Foucault, 2014).

Whilst the connection between weather and sales has long been acknowledged (Steele, 1951; Maunder, 1973), research to understand exactly how the weather impacts sales is scarce (Dell et al., 2014). For years, limited access to reliable weather data across large geographical areas has reduced the ability and motivation of researchers to investigate the effects of weather on business activity. This is no longer true, as access to quality data is now almost unlimited through cloud-based platforms, ready to be used and combined with business data to take better decisions (IBM, 2015).

Further incentives to understand the exact contribution of weather to sales performance arise from the finance and insurance industries, as new indexbased weather risk management tools to automatically compensate for both sales losses and increased costs caused by adverse weather are now available (Hershey and Breslin, 2015). Today, businesses are no longer compelled to 
cope with the weather but can respond to disruptive weather events.

Index-based weather hedging instruments offer features of interest to the majority of industries seeking protection against the financial consequences of adverse weather. However, industrial firms by and large have not widely used them to hedge weather risks (Huault and Weiss-Rainelli, 2011). Barriers to effective corporate risk management to reduce the likelihood of business failure include a lack of information about the nature, immediacy, and magnitude of the company's risk exposure. Companies also struggle with the inability to act on information concerning their risks, including concerns about potentially high costs of risk mitigation strategies such as premiums to hedge these risks (Bank, 2013). A lack of knowledge and understanding on how external events can interact with the business is a key feature of business failure (Carter and Auken, 2006). Small businesses and start-ups are even more vulnerable to weather risks, as they hedge even less than large corporations (Judge, 2006; Collier et al., 2016). Closing the information gap surrounding a company's exposure to weather risks will allow companies to proactively monitor their exposure and identify early warning signals of decline to prevent business collapse (Amankwah-Amoah et al., 2016). Therefore, we propose a methodology to determine the maximum potential loss resulting from the accumulation of weather risks. Further, using the case study of the effects of the weather on UK retail sectors, we illustrate how managers can take measures to mitigate their weather risk exposure.

Building from Maunder (1973) and Toeglhofer et al. (2012), we test the relationship between abnormal weather and sales using weather-sensitivity models in which the only unknown explanatory variable is a weather variable 
(Pres, 2009). The weather variable of the model is used to determine the weather-driven historical sales loss probability distribution. It is also used to structure weather index-based financial instruments aimed at mitigating the risk of lost sales.

The next section sets out the definition of weather risks and defines the scope of the review. Following the methodology and empirical results, we provide an example of risk mitigation and outline directions for future research.

\section{Literature Review}

Our research is related to three streams of the literature, namely, (i) weather and economics, (ii) business failure prediction, and (iii) weather risk management.

\subsection{Weather and business activity}

Weather affects production and consumption in a variety of activity sectors, most particularly agriculture, energy, food and beverages, tourism, transportation, entertainment, mining, apparel, construction and retail (Deschênes and Greenstone, 2007; Murray et al., 2010; Mirasgedis et al., 2014; Subak et al., 2000; Day et al., 2013; Fergus, 1999; Steinker and Hoberg, 2014).

Unlike many exogenous variables, the normal value of weather on any given day, in any given place, is known. It is the average value of weather observations, also called normal seasonal value, and meteorologists calculate it by averaging observation values such as temperature or precipitation of a given day over a 30-year period. The current calculation period for normal seasonal weather is 1981-2010 (as defined by the World Meteorological Organization). 
Consequently, since seasonal weather is known, businesses are able to plan for the seasonality of their activity and organize marketing and production accordingly, and so long as the weather remains normal, it does not disrupt sales.

The risk to which businesses are exposed to the weather is the risk that abnormal weather patterns develop and directly affect consumers' behavior in terms of what products they buy, where, and in what quantity, or how the weather indirectly affects the price of commodities through unexpected high or low yields (Maunder, 1973; Barsky and Miron, 1989). Weather risks can be catastrophic or non-catastrophic. Financial losses caused by catastrophic events such as hurricanes and tornadoes can easily be transferred using traditional insurance. They are not the focus of our analysis. Non-catastrophic weather risks stem from the accumulation of day-to-day deviations from normal weather. For example, above-normal temperatures in winter reduce demand for heating and adversely impact the revenues of energy companies (Huntington, 2007; Blázquez et al., 2012), whilst below-normal precipitations decrease agricultural yields (Yu et al., 2014) and drive sales of tourism and recreational activities higher (Martin, 2005). They refer to excessive levels of heat, cold, precipitation or wind (Corbally and Dang, 2002). In this paper, weather risk is defined as the extent to which adverse weather can cause financial losses (Clemmons, 2002).

Examining the weather risk of a business unit or sector can be complex. Whilst weather mostly affects the volume of activities and therefore the quantity of goods sold, there are situations where weather affects both volume and price. In some industries (e.g., the energy industry) the relationship 
between weather and sales is straightforward. However, in most cases too little knowledge is available. Thus, the identification of suitable weather variables or indexes is imperative to determine how weather impacts sales (Toeglhofer et al., 2012). This comprises selecting weather conditions in a list of weather variables for a specific time period and geographic area that may have an impact on a business' revenues or costs, and in establishing an empirical relationship between sales and weather. This defines the weather-sensitivity relationship, which provides the two parameters required to construct a financial product to protect against adverse weather: the weather index (which has the most significant impact on the business' financial results), and its multiplier effect on the business' financial loss defined in monetary units.

Many studies have established a relationship between sales and weather, but research on how to estimate the potential loss caused by adverse weather and how to mitigate them is scarce (Dell et al., 2014). The goal of modeling is usually to develop predictive models so that businesses can take corrective actions. A company like Tesco has used weather forecasts for years in an attempt to reduce costs and avoid wasting food (Werdigier, 2009). The use of short-term weather forecasts to improve demand forecast can prove effective to adapt marketing, promotion and staff costs only to the extent that weather forecasts are reliable, which in practice means less than a week (Steinker et al., 2017).

When weather conditions are on average unfavourable over days, weeks or entire seasons, falling sales cause reduced cash-flows that have the potential to generate financial distress, especially if adverse weather conditions are sufficiently severe (Beaver, 1966). For all companies that order goods weeks 
or months in advance of the selling season, what is required is not a model to predict, but a weather-sensitivity model to determine the parameters necessary to structure a financial cover that compensates for reduced cash-flows, and that improves the financial stability of the company.

From a methodological point a view, the weather-sensitivity relationship is established through correlation or regression analysis. Steele (1951)'s seminal work consisted of observing the sales of a department store in Iowa and performing a multiple regression analysis with sales as a dependent variable and whatever explanatory weather variables were needed to fully express the weather situation. Ten years later, Linden (1962) related sales of winter coats and average monthly temperatures in New-York. The simplest method known as Best/Worst approach was developed by Clemmons and Radulski (2002). The relationship is obtained by dividing the difference between best and worse annual sales and best and worse weather index observed over the analyzed years. The Analog approach focuses on anomalous weather events (e.g. the unusually hot summer in the UK in 1995) to evaluate the impact of future analog events on economic performance (Giles and Perry, 1998; Agnew and Thornes, 1995). More recent studies also used lagged dependent variables as explanatory variables in regression models (Agnew and Palutikof, 2006; Murray et al., 2010; Bahng and Kincade, 2012), or moved the discussion to analyzing the potential effects of abnormal weather on sales (Tran, 2016; Arunraj and Ahrens, 2016). Toeglhofer et al. (2012) and Bertrand et al. (2015) opened new avenues by proposing a method to provide both the potential loss caused by adverse weather and its probability of occurrence, by extending the concept of Value-at-Risk to weather risks. Value-at-Risk (VaR) is a financial 
measure of the exposure of asset returns to day to day volatility (Linsmaier and Pearson, 2000). By analogy, Weather-VaR is the maximum expected loss in sales caused by adverse weather over a given period of time for a given level of confidence.

\subsection{Weather risk and financial distress}

Financial distress is the situation that a business has certain kind of financial difficulties (Sun et al., 2014). Even though definitions of financial distress vary from insufficiency of resources to inability to fulfill its financial obligations (Walsh and Cunningham, 2016), they are based on the theoretical framework of cash flow. Beaver (1966) compares a business to a reservoir filled up with cash flows, made of inflows (sales) and outflows (operating expenses). Financial distress occurs when the reservoir starts to drain.

Financial Distress Prediction (FDP) is the core process of financial distress early warning (Sun et al., 2014; Amendola et al., 2017). Academic research on FDP has gone on for almost eighty years (Fitzpatrick, 1932), and has been dominated by financial ratio analysis (Almamy et al., 2016). Early works were based on univariate analysis, focusing on one ratio at a time, such as cash-flow to debt ratio (Beaver, 1966), until Altman (1968) questioned this approach and introduced multivariate analysis.

Cash flows and financial ratios have long been used as variables in the development of business failure prediction models (Casey and Bartczak, 1985; Gahlon and Vigeland, 1988; Gombola et al., 1987). These models test the risk that a deterioration in cash flows may prevent businesses from meeting debt repayment obligations. The probability of failure increases with insufficient cash flows. From the perspective of theoretical analysis, financial distress has 
different degrees. Moderate financial distress may just be temporary cash flow difficulty, while serious financial distress is business failure or bankruptcy (Sun et al., 2014). From the perspective of empirical research however, mostly due to a lack of data availability, financial distress is often defined as a stage of liquidation or bankruptcy.

Financial distress however is a dynamic ongoing process, and is the result of abnormality of external factors that interact with business operations for a period of time, from days or months to years (Figure 1). External factors, such as competitors, tax and legal environments, and environmental jolts are disruptive. Meyer (1982) describes environmental jolts as transient perturbations whose occurrences are difficult to foresee and whose impacts on organisations are disruptive and potentially inimical.

\section{**** INSERT FIGURE 1 ABOUT HERE ****}

Schumpeter's view of creative destruction emphasizes the role of environmental jolts in their capacity to disrupt organisations. The effects of unexpected and sudden environmental changes have often been studied in the context of disruptions to economic systems and activities, but the focus has been limited to external factors such as competition, technology, innovation, tax or business cycles, and the development of corresponding risk or crisis adaptation mechanisms (Tushman and Anderson, 1986; Covin and Slevin, 1989; Poole and Van de Ven, 2004).

Following the integrative process framework of organisational failure proposed by Amankwah-Amoah et al. (2016), we argue that weather events act as hostile jolts (external factors) that have the potential to repeatedly cause 
a decline in sales, cash flows and profitability (stages of decline), and lead to organisational failure.

Dealing with unexpected changes in organisations' environments has been an ongoing challenge for organizational managers (Linnenluecke and Griffiths, 2010). Sudden changes have often been analysed in the framework of disruptions to economic systems, and have resulted in calls for understanding and developing risk and crisis adaptation mechanisms (Kovoor-Misra et al., 2000; Meyer, 1982) or the deployment of product, process, and organizational change innovations (Poole and Van de Ven, 2004). To the best of our knowledge, the role of abnormal weather as potential external factor likely to disrupt sales, reduce cash flows and generate financial distress, and the development of mitigating mechanisms have not been addressed.

Yet, empirical evidence shows that few environmental factors exhibit as much uncertainty and potential to generate large financial losses as severe weather events and climate variability associated with climate change (Barnett, 2001). In the UK, in 2015, two thirds of small businesses declared to have been negatively affected by weather over the previous three years (Federation of Small Businesses, 2015). Severe weather events caused disruption to people (customers and staff) and logistics (supply chain, utilities and transport). Whilst $93 \%$ of small businesses believe severe weather poses a risk to their businesses, half say they do not get information from any source about how to mitigate the consequences of severe weather. At the very beginning of 2016, Sports Direct, the UK's largest sporting retailer, operating roughly 670 stores worldwide issued a profit warning announcing that it expected to miss its target for underlying profits due to unexpectedly warm weather 
over the Christmas period. The warning sent shares falling 14\%. In 2015, industry leaders released no less than 18 profit warnings directly attributed to abnormal weather. An unusually warm autumn in the UK led to retailers lamenting loss revenues in profit warnings, each causing shares to fall. Esprit, Boohoo, N Brown, SuperGroup and Shoe Zone all experienced well below forecast revenues.

According to the UK National Statistics (ONS), the retail sector has consistently exhibited the highest number of business failures between 2011 and 2015 , accounting on average for $10 \%$ of the total number of failures. Even large companies declare that they have already started to feel the financial consequences of abnormal weather (Bloomberg et al., 2014). The likely increase in frequency and intensity of weather events should encourage researchers to revisit theories of organizational adaptation in order to incorporate a wider perspective of organizational resiliency to impacts of severe weather events (Linnenluecke and Griffiths, 2010). Such research begins with investigating and understanding the extent to which abnormal weather affects business cash flows.

\subsection{Mitigating non-catastrophic weather risks}

For over two decades, policy makers have urged the financial sector to improve knowledge on weather-related risks, recognise them as a decision factor in business planning, lending and portfolio management, and develop

efficient risk transfer products to deal with them (IPCC, 1990; UNEP-FI, 2006).

Over the same two decades, the number and the intensity of abnormal and severe weather events has risen. The Intergovernmental Panel on Climate 
Change forecasts that heat waves and severe rainfall are likely to continue to increase in the 21st century (2013). In the United Kingdom, for instance, the standard deviation of temperature anomalies measured as the difference between observed and normal temperatures, has doubled since 2000. The standard deviation of weather variables is now at about similar levels as the volatility of other financial variables such as foreign exchange rates, interest rates and commodity prices, but the trend is up, which implies that weather risks have become environmental jolts that have the potential to disrupt the economic activity and generate business failures, and mitigating mechanisms must be considered and tested (Meyer, 1982).

Efficient risk management can only take place on the condition that the risks are perfectly defined (Merna and Al-Thani, 2011). Applied to weather risk management, this means identifying the weather parameters that have impacts on financial results, and understanding exactly how they affect these results. Once this is done, a business may determine if its exposure to weather is material, and if so, the extent to which it can withstand the financial losses incurred by the weather without hedging this risk. The success of coming up with the best hedge in most cases lies in the accuracy of the evaluation of the weather parameters (Pres, 2009).

Index-based weather risk management instruments were introduced in 1997 to automatically compensate the financial losses when the weather index exceeds a predefined level (Muller and Grandi, 2000). They work like any other traditional hedging instruments except that the index on which they are settled is a weather index. The index can be average temperature thresholds, rainfall levels, wind speeds or any combination of variables that represent the 
risk to which the business is exposed. The payment is triggered by and linked to the weather index, not the actual financial loss incurred by the business. The first weather hedging products were derivative instruments designed for the US energy market some 20 years ago to protect energy distribution companies from above-average winter temperatures resulting in lower sales and profits (Dischel, 2002). Standard contracts based on temperature were later launched on the Chicago Mercantile Exchange during the summer 1999 to address weather risks to a city or a region, and contracts based on snowfall, frost and rain were introduced several years after. However, most of weather hedge contracts continue to be bespoke contracts, and respond to the specific needs of each business situation (Jewson and Brix, 2005).

The details and usage rates of such instruments has remained largely confidential (Huault and Weiss-Rainelli, 2011). The cost of transacting has been traditionally high as many players existed along the supply chain between the potential client and the risk taker, each requiring fees and commissions (e.g. brokers, weather data providers, weather-sensitivity analysts, product structurers, lawyers, risk capacity providers and insurers if the product is packaged as an insurance instead a financial instrument).

Today, prompted by better access to free and reliable historical weather data, new companies (e.g. ClimateSecure or Speedwell) integrate all these functions in order to analyse clients' risks, structure and distribute products. Some have developed web-based underwriting and pricing platforms to provide easy access for businesses of any size to cover weather risks almost anywhere in the world, for any amount, for any period (Hershey and Breslin, 2015).

In addition, through the same platforms, the pricing of weather derivatives 
has become more transparent. The most common pricing technique is the burn analysis, which looks at how the financial hedges would have performed in previous years, and averages the payout to calculate the cost of the product (Jewson and Brix, 2005). Other pricing methods include simulating the value of the weather index at the expiry date of the product (e.g. Monte Carlo methods) or using more sophisticated stochastic models that replicate the weather index (Dorfleitner and Wimmer, 2010; Pirrong and Jermakyan, 2008; Cabrera et al., 2013). It is worth noting that, since the level of volatility of weather variables is at similar levels as the volatility of financial indexes, there is no reason for businesses to hedge financial risks and continue to bear weather risks (Pres, 2009).

\subsection{Hypotheses}

Drawing upon the UK retail sectors for empirical evidence, we formulate the following hypotheses:

1. Abnormal weather has an incidence on sales (cash inflows)

2. Each retail sector exhibits a different sensitivity to the same abnormal weather conditions

3. A breakdown analysis per season provides a more accurate estimate of weather risks

4. Abnormal weather has the potential to cause large sales losses (environmental jolts)

5. Tailor-made weather index-based financial products can reduce the risk of large losses (unexpected lower cash inflows) and the uncertainty on sales cash flows caused by abnormal weather 


\section{Methodology and data}

\subsection{Methodology}

The objective of the weather-sensitivity analysis is to determine the weather index that has the most impact on sales, to define how a unit change in the index affects sales, and to evaluate the maximum potential loss caused by adverse conditions. We follow the methodology presented in Bertrand and Parnaudeau (2017).

Step 1 of the methodology consists in testing for each season the correlation between the change in monthly sales year on year, and abnormal temperature, precipitation and humidity rate, to select the most influential weather variables. In step 2, the selected weather variables are used to estimate the empirical relationship between weather and sales, for each season, using the following model:

$$
\Delta S_{m, s}=\alpha \Delta S_{m-1, s}+\beta W_{m, s}+c+\gamma G D P_{m, s}+\epsilon_{m, s}
$$

$\Delta S_{m, s}=\frac{S m, s-S_{m, s-12}}{S_{m, s-12}}$ is the monthly growth rate of sales (volumes) year-onyear for month $m$ during season $s$, with $s=$ (spring, summer, autumn, winter). The choice of the variable $\Delta S_{m-1, s}$ follows national statistics reporting and management practices that compare sales performance of a given month from one year to the other (Berry, 1987). The first month of spring, summer, autumn and winter are March, June, September and December respectively. $W_{m, s}$ is a weather variable that passed the correlation test in step 1 . In each model, there is only one weather variable at a time, for which we test the 
significance. If more than one weather variable is significantly correlated with sales for a given retail category, we build as many models as the number of correlated weather variables. This way, we can measure the impact of each weather variable independently, and avoid potential over-fitting issues. $G D P_{m, s}$ accounts for the economic situation of the country. Finally, c is a constant and $\epsilon_{m, s}$ is the disturbance term.

The parameters of the models are estimated using the Generalized Methods of Moments following Blázquez et al. (2012). The relevance of our GMM estimates is verified using Sargan tests of over-identification. The verification of the normality of the residuals is done using Gaussian distribution tests. Our results showed that the assumption of a normal distribution for the residuals appears to be reasonable (histogram of frequencies, skewness and kurtosis coefficients). The independence between residuals has also been verified on the basis of the autocorrelations and partial autocorrelations between the residuals. The residuals were not significantly different from a white noise series. All our tests are performed using the $\mathrm{R}$ statistical programming environment. For comparison purpose, several SARMA estimations have been realized without making any breakdowns in the sample. Results are available in Appendix (Table A.11).

In step 2, we keep the models that comply with all the tests. At this stage, we have selected for each weather-sensitive retail category and each season, the weather variable that impacts sales, and the extent to which it impacts them (the $\beta$ coefficient of the model).

Step 3 consists in playing back observed historical weather of all available years (usually 30 years) in the models, to build the historical loss occurrence 
distributions and determine the potential maximum losses caused by adverse weather.

\subsection{Data: The UK Retail Industry}

The retail industry is highly vulnerable to business failure (McGurr and DeVaney, 1998) and is believed to be one of the most exposed to the consequences of abnormal weather. In October 2014 for instance, the ONS explained that UK retail sales were down $0.7 \%$, partly due to warmer than usual weather affecting sales of winter clothing. In April 2013, retail sales were down 1.3\%. Again, the ONS attributed the drop in consumption to abnormal weather that impacted sales of garden furniture and barbecue food.

\section{**** INSERT TABLE 1 ABOUT HERE $* * * *$}

Retail sales data are collected from a sample of approximately 5,000 retailers across Great Britain. The sample represents the whole retail sector and includes all large retailers and a representative sample of smaller businesses. The known retail industry population is approximately 200,000 businesses and while the sample represents $2.5 \%$ of this population in terms of number of businesses the sample covers approximately $93 \%$ of all known turnover in the retail industry.

We analyse the impact of abnormal weather on monthly retail sales for all retail categories and all four seasons, but for concision, we chose to present the most significant results and limit the categories to the list displayed in Table 1. Our data set covers the period January 1989- August 2015. Retail sales express volumes bought in a month. 
Weather data is aggregated into variables for analysis, to a level which is consistent with the resolution of the economic data (Dell et al., 2014). Following Maunder (1973) and Parsons (2001), we aggregate weather at the national level using twelve weather stations spread across the UK, and a fixed set of population weights.

We use daily observations of temperature, precipitation and humidity rate. Humidity rate is the amount of water vapor in the air expressed as a percentage. It indicates the likelihood of precipitation, dew or fog. Humidity may result in consumer behaviors distinct from those caused by precipitation. Weather data is extracted from the National Oceanic and Atmospheric Administration GSOD database. The measure of abnormal weather in a given month is the average anomaly calculated as the average difference between the daily observed weather and its normal value.

\section{Results}

\subsection{Influential Weather Variables}

Table 2 provides correlations for each season for the retail categories we present. Within this list of categories, the highest number of significant correlations is observed for abnormal temperatures. Sales in sporting equipment, clothing, footwear and leather goods are all positively correlated to temperature anomalies in the spring season, which means that above-normal temperatures are associated with higher sales. In autumn, it is the opposite. Correlations are all negative: above-normal temperatures are associated with lower sales. In the summer, when temperatures are warmer than normal, sales in beverages are higher whilst sales in cultural goods (books and music) 
and home furniture are weaker. This is consistent with both Maunder (1973) and with anecdotal evidence discussed in section 1.

\section{**** INSERT TABLE 2 ABOUT HERE ****}

In spring, almost all retail categories exhibit a negative correlation between sales and precipitation, except for sales of music and household furniture: the sales of clothing, footwear, beverages, and cosmetics are all adversely affected by excess rain. In the summer however, abnormal rain is positively correlated to textiles, clothing and footwear, implying that excess rain drives more consumers to stores. Humidity rate provides very similar information to precipitation. It is interesting to note that the effects of excess humidity in the spring has a stronger correlation with the sales of beverages and cosmetics than rain. Also in the summer, humidity rate is positively correlated to the sales of books and carpets.

\subsection{Weather-sensitivity per season}

The weather variables selected in the previous section are used to model the relationship between sales and weather for spring, summer, autumn and winter. Examples of weather-sensitivity models that comply with Sargan and serial correlation in residuals tests presented in Tables 4, 5 and 6 illustrate the incidence of weather on sales (Hypothesis 1). These tables display both models with and without $G D P$. In our case, the ultimate objective of modeling is to construct a financial protection against unfavourable weather conditions, for a given business in a given sector. This requires defining two parameters: type of weather exposure (one or more weather indices that have a crucial 
impact on financial results), and the sensitivity coefficient $(\beta)$ that describes the size of possible losses. Pres (2009), who reviewed all available methods to determine weather-sensitivity models, stresses that "usually in weatherrisk estimating, only three categories of weather indices (air temperature, precipitation and wind speed) and one financial variable (sales volume, total income or total margin) are used". Hence, in the next sections, we will only use models without GDP.

In Table 4, we note that retail sectors exhibit very different sensitivities to the same weather variable (Hypothesis 2). In autumn for instance, a positive deviation of $1^{\circ} \mathrm{C}$ increases sales of alcoholic drinks by more than $11 \%$, whilst the same deviation in temperature causes sales of footwear to decrease by about $1 \%$.

We broke down our analysis by season to avoid the wash-out effects discussed by Lazo et al. (2011) who concluded that the contribution of weather to the US economic activity was lower than expected. Table 3 is an illustration of this wash-out effect. A positive deviation of $1^{\circ} \mathrm{C}$ in spring causes sales of footwear to increase by $3.238 \%$ and sales of clothing to increase by $1.648 \%$. The same positive deviation of $1^{\circ} \mathrm{C}$ in autumn causes sales to decrease by $3.067 \%$ and $1.133 \%$ respectively. This is easily explained because spring and autumn collections are different. Small pieces like tee-shirts and skirts sell more in warm springs, whilst larger garments such as jumpers and coats sell less in warm autumns.

Seasonal patterns are often addressed using SARMA models. The use of SARMA models for footwear and clothing sales (see Table A.11 in Appendix) supports the presence of significant seasonal effects $\left(S A R(4)=0.129^{* * *}\right.$ and 
$0.270^{* * *}$ resp.) while the Breusch-Godfrey tests confirm the absence of serial correlations in the residuals. GDP holds a marginal significance, but abnormal temperature $\left(T e m p_{m}\right)$ is a strong explanative variable for both categories, with a $\beta$ of $1.945^{* * *}$ and $0.787^{* * *}$ respectively. The low intrinsic value of both coefficients reflects the wash-out effects. 2013 weather conditions in the UK illustrate our discussion. 2013 was almost a normal year, with an average temperature for the year $0.11^{\circ} \mathrm{C}$ above normal. Using SARMA models, we estimate the contribution of weather to the sales of footwear and clothing to be $+0.19 \%$ and $0.08 \%$ respectively $\left(\beta * 0.11^{\circ} \mathrm{C}\right)$, which does not reconcile with the type of weather effects experienced by retailers in 2013.

If we measure this effect using a breakdown analysis by season, the picture is very different. In 2013 , spring was abnormally cold $\left(-2.11^{\circ} \mathrm{C}\right)$ and autumn was abnormally hot $\left(+1.01^{\circ} \mathrm{C}\right)$. Using $\beta$ coefficients in Table 3 , we calculate the cumulative impact of abnormal weather of $-9.9 \%$ for footwear sales and $4.6 \%$ clothing sales, which is consistent with empirical evidence.

**** INSERT TABLE 3,4,5,6 ABOUT HERE ****

\subsection{Estimation of sales losses caused by adverse weather}

The weather-sensitivity model provides a business with the opportunity to understand how a change in weather conditions will affect sales of a given product in the considered season. To evaluate a weather risk exposure, a first approach consists in calculating the average and maximum losses caused by adverse weather, based on historical weather observations. We use 30 years of historical data to calculate normal weather.

Table 7 provides the average and the maximum deviations from normal 
weather for temperatures in the UK. The same information is provided for precipitation and humidity rate in appendix (Table A.12). If we consider the retail sector of alcoholic drinks in autumn, since $\beta$ is equal to 11.445 , the average deviation from normal sales in autumn is $5.3 \%\left(11.445\right.$ times $\left.0.47^{\circ} \mathrm{C}\right)$. We proceed in the same way to calculate the maximum loss. In the case of alcoholic drinks, since $\beta$ is positive, adverse weather is a negative deviation. As a result, the maximum loss caused by adverse weather in autumn is $29.4 \%$ (11.445 times $\left.2.45^{\circ} \mathrm{C}\right)$. Given retail margins in this sector, this level of sales loss and shortage in cash inflows is an important disruption, likely to drive any retailer into financial distress (Hypothesis 4).

\section{**** INSERT TABLE 7 ABOUT HERE ****}

A second approach consists in estimating the probability of occurrence of sales losses, using a probabilistic distribution of abnormal weather. Based on the 30-year historical distribution of abnormal weather, a common practice consists of smoothing the historical distribution with a process called kernel smoothing (Brix et al., 2002), whereby the probability density function (PDF) $f$ of the index distribution taken at point $x$ is given by:

$$
\hat{f}(x)=\frac{1}{n} \sum_{i=1}^{n} \frac{1}{h} k\left(\frac{x-\tilde{I}_{i}}{h}\right)
$$

In this PDF, the degree of smoothing is determined by the bandwith $h$. Whereas the choice of smoothing function is not critical, the bandwith selection is important for the overall shape of the estimated distribution: the larger $\mathrm{h}$, the more smoothing is obtained. The kernel PDF function is used to 
estimate the probability that a weather anomaly exceeds a certain threshold. The $5 \%$ threshold is often used to refer to severe abnormal weather, as it is only observed $5 \%$ of the time (Linsmaier and Pearson, 2000). A summary of these thresholds is provided in Appendix for UK temperatures, precipitations and humidity rates (Table A.12).

The distribution is then used in the weather-sensitivity models to estimate the probability that a loss in sales caused by adverse weather exceeds a certain threshold. For instance, based on the distribution of UK abnormal temperatures in autumn, there is a $5 \%$ probability that negative temperature deviations exceed $-1.81^{\circ} \mathrm{C}$. In the case of alcoholic drinks, this means that there is a $5 \%$ probability that the loss caused by adverse weather in autumn exceeds $20.7 \%$ of sales. Using the same distribution, the probability that the loss exceeds $10 \%$ of sales is $17 \%$. It is important to note that, since abnormal weather in a given season is statistically independent from abnormal weather in an other season, the effects of abnormal weather on sales for the year are cumulative. In the retail of footwear, the maximum loss in sales caused by abnormally cold temperatures is $6.8 \%$ in spring $\left(3.238\right.$ times $\left.-2.11^{\circ} \mathrm{C}\right)$ and $7.5 \%$ in autumn $\left(-3.067\right.$ times $\left.2.45^{\circ} \mathrm{C}\right)$. To conclude this section, we find that in many retail sectors, the maximum loss caused by adverse weather is a reduction in cash inflow that is material and large enough to disrupt many businesses (Hypothesis 4).

4.4. Mitigating the effects of non-catastrophic weather risks: case of the alcoholic and other beverage retail sector in autumn

In this section, we show how index-based weather financial instruments can be used to lower the risk of experiencing large losses in sales caused by 
adverse weather and reduce the high level of uncertainty on sales variance due to abnormal weather variability year on year (Hypothesis 5). Index-based weather products are mostly sold by insurance and reinsurance companies. A business can implement index-based weather instruments to follow three different hedging strategies. The first strategy consists in eliminating completely the consequences of abnormal weather. This is done with a swap. In a swap, there is no upfront payment. The business is compensated to offset the loss in margins in case of adverse weather. Conversely, the business gives up all potential additional margins due to favorable weather conditions. The second strategy consists in buying a protection against the consequences of adverse weather and keeping $100 \%$ of potential additional margins in case of favorable weather. This is called an option. Finally, the third strategy is a combination of options, called a collar or a tunnel. A collar protects the business against the consequences of adverse weather, just like an option, but the business gives up a portion of potential additional margins in case of favorable weather. As a result, it is less expensive that the straightforward option strategy.

The cost of index-based weather instruments is the fair value to which a margin, called the load factor, is added by the insurance company. The fair value of the weather index-based instrument is calculated using a burn analysis. The burn analysis looks at how the instrument would have performed under all historical weather observations available. In the case of the retail of alcoholic drinks, we have 30 years of weather observations that we can use to evaluate the fair value of various instruments.

To illustrate this, we consider a business that has normal sales of $£ 100 \mathrm{~m}$ 
and a profit margin of $10 \%$. We consider three hedging strategies: a swap, an option that protects the business if adverse weather causes margins to drop by more than $10 \%$, and a collar that protects the business if sales fall by more than $10 \%$ because of weather but limits additional margins to $10 \%$ in case of favorable weather.

Figure 2 is a reconstruction of profits and losses caused by abnormal weather conditions observed over the last 30 years. In other words, the weather conditions observed in 1986 applied to our model would produce an additional sales of $3 \%$. Weather conditions observed in 2007 would generate a loss of $21 \%$. The maximum loss of $29 \%$ corresponds to the weather conditions observed in 2012.

Table 8 is the burn analysis and the reconstruction of cash flows under all available weather conditions observed between 1986 and 2014, for four possible strategies: no hedge, an option, a collar, and a swap. If the business does not hedge, the maximum loss is $£ 2.9$ million and the standard deviation is $£ 1.3$ million. With an option, the loss is capped at $£ 1$ million, and the standard deviation is reduced to $£ 1.1$ million. With a collar, the maximum loss is still $£ 1$ million, but the standard deviation is further reduced to $£ 0.9$ million. Finally, with a swap, there is no loss and by definition the standard deviation is equal to zero.

The cost of the option or the collar is the burn to which a load factor is added. The load factor is usually a fraction of $\sigma$, the standard deviation of the cash flows used to determine the burn (Jewson and Brix, 2005). Using $10 \%$ of $\sigma$ as the load factor, the cost of the option works at to be $£ 194969$ or $1.95 \%$ of the margin. Similarly, the cost of the collar is $£ 82872$ or $0.83 \%$ 
of the margin.

The efficiency of various hedging strategies is demonstrated in Table 9 (Hypothesis 5). For a cost that represents $0.19 \%$ of sales, an option reduces the maximum loss in margins from $29 \%$ to $10 \%$, and reduces the variability of margins by $17 \%$ from $13.44 \%$ to $11.16 \%$. The collar reduces further the variability of margins by $34 \%$, from $13.44 \%$ to $8.88 \%$.

\section{**INSERT TABLE 8, FIGURE 2 AND TABLE 9 ABOUT HERE**}

\section{Conclusion}

This study has important implications for business failure research as it brings into focus the importance of considering increasing non-catastrophic weather risks as a new environmental jolt that can generate financial losses and drops in cash inflows likely to precipitate business failure, especially in the case of small or new businesses.

We show that is now possible to establish a clear diagnosis of business exposure to weather. Using monthly UK retail sales, we identify each weather parameter that impacts sales in several retail categories, and show the extent

to which, each season, adverse weather can cause significant sales losses and shortages of inflows.

We demonstrate that knowledge of weather risks makes it possible to structure simple weather index-based hedging instruments, to economically and efficiently reduce the risk of large financial losses caused by severe weather events, and decrease the volatility of future cash-flows exposed to weather. Today, weather risk management is still in its early days, and the majority of businesses do not hedge against weather risks, nor do they have an accurate 
view on how much is at risk. We contribute to raising awareness on the need for weather-sensitive businesses to make use of the methodology and weather data in order to get a clear picture of their exposure and implement operational or financial strategies to mitigate the financial impact of abnormal weather.

In using a simple method to apprehend concepts of short-term weather impacts, we are moving the discussions concerning climate change and its effects on the private sector within managerial boundaries. Whereas most studies that analyze the potential effects of climate change on the private sector address a time horizon that is too far out for managers and investors to be concerned, we provide retailers with a practical measure of their risk in the short-term, on a seasonal basis.

As climate variability is likely to continue to increase, we expect more research will be conducted to quantify the role of weather in contributing to business financial distress and business failure. We also anticipate growing interest from scholars and practitioners to evaluate the contribution of weather risk management to business sustainability.

\section{References}

Agnew, M. D. and Palutikof, J. P. (2006). Impacts of short-term climate variability in the uk on demand for domestic and international tourism. Climate Research, 31(1):109-120.

Agnew, M. D. and Thornes, J. E. (1995). The weather sensitivity of the UK food retail and distribution industry. Meteorological Applications, 2:137-147. 
Almamy, J., J. Aston, J., and Leonard, N. (2016). An evaluation of altman's z-score using cash flow ratio to predict corporate failure amid the recent financial crisis: Evidence from the uk. Journal of Corporate Finance, $36: 278-285$.

Altman, E. (1968). Financial ratios, discriminant analysis and the prediction of corporate bankruptcy. The Journal of Finance, 23(4):589-609.

Amankwah-Amoah, J., Boso, N., and Antwi-Agyei, I. (2016). The effects of business failure experience on successive entrepreneurial engagements: An evolutionary phase model. Group and Organization Management, pages $1-32$.

Amankwah-Amoah, J. and Zhang, H. (2015). Business failure research: a review of the chinese experience. International Journal of Foresight and Innovation Policy, 10:180-197.

Amendola, A., Giordano, F., Parrella, M. L., and Restaino, M. (2017). Variable selection in high-dimensional regression: a nonparametric procedure for business failure prediction. Applied Stochastic Models in Business and Industry, 33(4):355-368.

Anderson, P. and Tushman, M. (2001). Organizational environments and industry exit: The effects of uncertainty, munificence and complexity. Industrial and Corporate Change, 10:675-711.

Arunraj, N. S. and Ahrens, D. (2016). Estimation of non-catastrophic weather impacts for retail industry. International journal of retail and distribution management, 44:731-753. 
Bahng, Y. and Kincade, D. (2012). The relationship between temperature and sales: sales data analysis of a retailer of branded women's business wear. International Journal of Retail and Distribution Management, 40(6):410426.

Bank, W. (2013). Risk and opportunity: Managing risk for development. Technical report, International Bank for Reconstruction and Development, Economic Research Report.

Barnett, J. (2001). Adapting to climate change in pacific island countries: The problem of uncertainty. World Development, 29:977-993.

Barsky, R. B. and Miron, J. A. (1989). The seasonal cycle and the business cycle. Journal of Political Economy, 97(3):503-534.

Beaver, W. (1966). Financial ratios as predictors of failure. Journal of accounting research, 4:71-111.

Berry, D. (1987). A method to portray and analyze sales performance. Industrial Marketing Management, 16(2):131-144.

Bertrand, J.-L., Brusset, X., and Fortin, M. (2015). Assessing and hedging the cost of unseasonal weather: Case of the apparel sector. European Journal of Operational Research, 244(1):131-144.

Bertrand, J.-L. and Parnaudeau, M. (2017). No more blaming the weather: a retailers approach to measuring and managing weather variability. International Journal of Retail and Distribution Management, Forthcoming.

Blázquez, L., Boogen, N., and Filippini, M. (2012). Residential electricity 
demand in spain: new empirical evidence using aggregate data. Working Paper.

Bloomberg, M. R., Paulson, H. M., and Steyer, T. F. (2014). Risky business: the economic risks of climate change in the United States. Report, Bloomberg.

Brix, A., Jewson, S., and Ziehmann, C. (2002). Climate risk and the weather market, chapter Weather derivative modelling and valuation: a statistical perspective, pages 126-150. Risk Books, London, United Kingdom.

Cabrera, B., Odening, M., and Ritter, M. (2013). Pricing rainfall futures at the cme. The Journal of Banking and Finance, 37:4286-4298.

Carter, R. and Auken, H. V. (2006). Small firm bankruptcy. Journal of Small Business, 44:493-512.

Casey, C. J. and Bartczak, N. J. (1985). Using operating cash flow data to predict financial distress: Some extensions. Journal of Accounting Research, 23:384-401.

Clemmons, L. (2002). Weather Risk Management: Markets, Products, and Applications, chapter Introduction to weather risk management, pages 3-13. Ed. E. Banks, New York: Palgrave Macmillan.

Clemmons, L. and Radulski, D. (2002). Weather Risk Management: Markets, Products, and Applications, chapter The economics of weather, pages 25-58. Ed. E. Banks, New York: Palgrave Macmillan. 
Collier, B., Haughwout, A., Kunreuther, H., Michel-Kerjan, E., and Stewart, M. (2016). Firms management of infrequent shocks. National Bureau of Economic Research, No. w22612.

Corbally, M. and Dang, P. (2002). Weather Risk Management: Markets, Products, and Applications, chapter Underlying markets and indexes, pages 87-103. Ed. E. Banks, New York: Palgrave Macmillan.

Covin, J. and Slevin, D. (1989). Strategic management of small firms in hostile and benign environments. Strategic Management Journal, 10:75-87.

Day, J., Chin, N., Sydnor, S., and Cherkauer, K. (2013). Weather, climate, and tourism performance: A quantitative analysis. Tourism Management Perspectives, 5:51-56.

Dell, M., Jones, B., and Olken, B. (2014). What do we learn from the weather? the new climate-economy literature. Journal of Economic Literature, 52:740-798.

Deschênes, O. and Greenstone, M. (2007). The economic impacts of climate change: Evidence from agricultural output and random fluctuations in weather. American Economic Review, 97(1):354-385.

Dischel, R. S. (2002). Climate risk and the weather market, chapter Introduction to the weather market: dawn to mid-morning, pages 3-24. Risk Books, London, United Kingdom.

Dorfleitner, G. and Wimmer, M. (2010). The pricing of temperature futures at the chicago mercantile exchange. The Journal of Banking and Finance, 34:1360-1370. 
Dutton, J. (2002). Opportunities and priorities in a new era for weather and climate services. Bulletin of American Meteorological Society, 83(9):13031311.

Everett, J. and Watson, J. (1998). Small business failure and external risk factors. Small Business Economics, 11:371-390.

Federation of Small Businesses (2015). Severe weather, a more resilient small business community. Economic research report, The Federation of Small Businesses, ER-1, Arnold Zeller, ed.

Fergus, J. (1999). Where, when, and by how much does abnormal weather affect housing construction? Journal of Real Estate Finance and Economics, 18:63-87.

Fishta, E. and Casiraghi, L. (2016). Vivarte in talks to reset loan covenant. Bloomberg.

Fitzpatrick, P. (1932). A comparison of ratios of successful industrial enterprises with those of failed firms. ith those of failed firms.Certified Public Accountant. October, November and December, pages 598-605.

Foucault, G. (2014). L-gam acquires jardiland, the leading french garden and pet specialist. Press release.

Gahlon, J. A. and Vigeland, R. L. (1988). Early warning signs of bankruptcy using cash flow analysis. Journal of Commercial Bank Lending, 70:4-15.

Giles, A. and Perry, A. (1998). The use of a temporal analogue to investigate 
the possible impact of projected global warming on the uk tourist industry. Tourism management, 19:75-80.

Gombola, M. J., Haskins, M. E., Ketz, E. J., and Williams, D. D. (1987). Cash flow in financial prediction. Financial Management, 16:55-65.

Gordon, M. (1971). Towards a theory of financial distress. Journal of Finance, $26: 347-356$.

Gustafson, K. (2016). A $\$ 500 \mathrm{~m}$ hit and a bleak forecast for retail. $C N B C$.

Hanley, M. (1999). Hedging the force of nature. Risk Professional, July/August:21-25.

Hershey, L. and Breslin, E. (2015). Meteo protect: Empowering the bottom line with weather modeling. SAP Startup focus.

Huault, I. and Weiss-Rainelli, H. (2011). A market for weather risk? conflicting metrics, attempts at compromise, and limits to commensuration. Organization studies, 32(10):1395-1419.

Huntington, H. (2007). Industrial natural gas consumption in the united states: An empirical model for evaluating future trends. Energy Economics, $29: 743-759$.

IBM (2015). Weather means business. White paper, IBM Analytics.

IPCC (1990). Climate change: the ipcc scientific assessment. Technical report, IPCC, Cambridge, United Kingdom. 
IPCC (2014). Climate change 2014: Impacts, adaptation and vulnerability. Report Intergovernmental Panel on Climate Change, IPCC.

Jewson, S. and Brix, A. (2005). Weather derivative valuation: the meteorological, statistical, financial and mathematical foundations. Cambridge University Press.

Judge, A. (2006). The determinants of foreign currency hedging by u.k. non-financial firms. Multinational Finance Journal, 10:1-41.

Kovoor-Misra, S., Zammuto, R., and Mitroff, I. (2000). Crisis preparation in organizationsprescription versus reality. Technological Forecasting and Social Change, 63(1):43-62.

Larsen, P. H. (2006). Estimating the sensitivity of U.S. economic sectors to weather. Working Paper Cornel University, SSRN 900901, Cornel University.

Lazo, J. K., Lawson, M., Larsen, P. H., and Waidmann, D. M. (2011). U.S. economic sensitivity to weather variability. Bulletin of American Meteorological Society, 92:709-720.

Linden, F. (1962). Consumer markets: merchandising weather. The Conference Board Business Record, 19(6):15-16.

Linnenluecke, M. K. and Griffiths, A. (2010). Beyond adaptation: Resilience for business in light of climate change and weather extremes. Business and Society, 49:477-511.

Linsmaier, T. and Pearson, D. (2000). Value at Risk. Financial Analysis Journal, 57(2):47-67. 
Martin, M. (2005). Weather, climate and tourism a geographical perspective. Annals of tourism research, 32:571-591.

Maunder, W. (1973). Weekly weather and economic activities on a national scale: an example using united states retail trade data. Weather, 28(1):2-19.

McGurr, P. and DeVaney, S. (1998). Small business failure and external risk factors. Journal of Business Research, 43:169-176.

Merna, T. and Al-Thani, F. F. (2011). Corporate risk management. John Wiley \& Sons.

Meyer, A. (1982). Adapting to environmental jolts. Administrative Science Quarterly, pages 515-537.

Milne, R. (2016). Late spring chills h\&m sales. The Financial Times.

Mirasgedis, S., Georgopoulou, E., Sarafidis, Y., Papagiannaki, K., and Lalas, D. (2014). The impact of climate change on the pattern of demand for bottled water and nonalcoholic beverages. Business Strategy and the Environment, 23(4):272-288.

Moulton, M., Thomas, H., and Pruett, M. (1996). Business decline pathways: environmental stress and organizational response. Journal of Management, 22:571-595.

Muller, A. and Grandi, M. (2000). Weather derivatives: A risk management tool for weather-sensitive industries. The Geneva Papers on Risk and Insurance. Issues and Practice, (2):273-287. 
Murray, K., Muro, F. D., Finn, A., and Popkowski, L. P. (2010). The effect of weather on consumer spending. Journal of Retailing and Consumer Services, 17(6):512-520.

Parsons, A. G. (2001). The association between daily weather and daily shopping patterns. Australasian Marketing Journal, 9:78-84.

Pirrong, C. and Jermakyan, M. (2008). The price of power: The valuation of power and weather derivatives. The Journal of Banking and Finance, $32: 2520-2529$.

Poole, M. and Van de Ven, A. (2004). Weather Risk Management: Markets, Products, and Applications, chapter Central issues in the study of change and innovation, pages 3-31. Oxford University Press.

Pres, J. (2009). Measuring non-catastrophic weather risks for businesses. The Geneva Papers on Risk and Insurance Issues and Practice, 34:425-439.

Ruckin, C. (2013). Vivarte in talks to reset loan covenant. Reuters.

Steele, A. T. (1951). Weathers effect on sales of a department store. journal of Marketing, 15:436-443.

Steinker, S. and Hoberg, K. (2014). The influence of weather in online retailing - an empirical analysis. Working paper.

Steinker, S., Hoberg, K., and Thonemann, U. (2017). The value of weather information for ecommerce operations. Production and Operations Management. 
Stiglitz, J. (1972). Some aspects of the pure theory of corporate finance: Bankruptcies and takeovers. The Bell Journal of Economics, 3:458-482.

Subak, S., Palutikof, J. P., Agnew, M. D., Watson, S. J., Bentham, C. G., Cannell, M. G. R., Hulme, M., McNally, S., Thornes, J. E., Waughray, D., and Woods, J. C. (2000). The impact of the anomalous weather of 1995 on the UK economy. Climatic Change, 44(1):1-26.

Sun, J., Li, H., Huang, Q., and He, K. (2014). Predicting financial distress and corporate failure: A review from the state-of-the-art definitions, modeling, sampling, and featuring approaches. Knowledge-Based Systems, 57:41-56.

Swamynathan, Y. and Layne, N. (2016). Macy's to cut jobs, shut stores amid weak holiday sales. Reuters.

Toeglhofer, C., Mestel, R., and Prettenthaler, F. (2012). Weather value at Risk: on the measurment of non-catastrophic weather risk. Weather, Climate, and Society, 4(3):190-199.

Tran, B. (2016). Blame it on the rain weather shocks and retail sale. Working paper UC, San Diego.

Tushman, M. and Anderson, P. (1986). Technological discontinuities and organizational environments. Administrative Science Quarterly, 31:439-465.

UNEP-FI (2006). Adaptation and vulnerability to climate change: the role of the finance sector. technical report, United Nations Environment Programme Finance Initiative. 
Walsh, G. and Cunningham, J. (2016). Business failure and entrepreneurship:

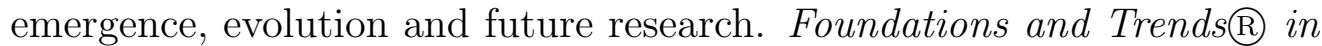
Entrepreneurship, 12(3):163-285.

Werdigier, J. (2009). Tesco, british grocer, uses weather to predict sales. New York Times.

WMO (2013). WMO statement on the status of the global climate in 2012. Report 1108, World Meteorological Organization.

Yu, C., Li, C., Xin, Q., and Zhang, J. (2014). Dynamic assessment of the impact of drought on agricultural yield and scale-dependent return periods over large geographic regions. Environmental Modelling and Software, 62:454-464. 


\title{
Understanding the economic effects of abnormal weather to mitigate the risk of business failures
}

\author{
Blinded Manuscript ${ }^{1}$
}

Abstract

Electronic Art Work Description

- Table 1: UK Retail Sales Stores (UK SIC 2007): single column fitting image

- Table 2: Extraction of correlations for selected retail categories: twocolumn fitting image

- Table 3: Wash-out effects in the case of footwear and clothing sales: single column fitting image

- Table 4: Extraction of models for which Temperature is an influential variable: two-column fitting image

- Table 5: Extraction of models for which Precipitation is an influential variable: two-column fitting image

- Table 6: Extraction of models for which Humidity Rate is an influential variable: two-column fitting image

- Table 7: 30 year statistics of UK abnormal temperatures: two-column fitting image 
- Table 8: Reconstructed net cash flows due to abnormal weather in ; Maximum loss in margin in bold: two-column fitting image

- Table 9: Efficiency of weather hedging in reducing maximum loss and cash-flow uncertainty: two-column fitting image

Appendix:

- Table A.10: weather stations and population weights: two-column fitting image

- Table A.11: SARMA Models: Extraction of Results for Temperature and Precipitation, (1989-2015): two-column fitting image

- Table A.12: Historical unseasonal weather Statistics: two-column fitting image

\section{Tables}

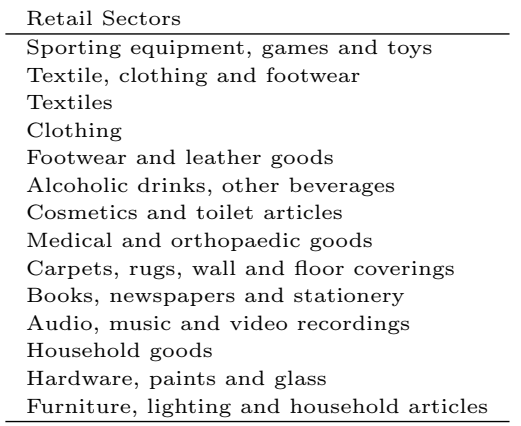

Table 1: UK Retail Sales Stores (UK SIC 2007) 


\begin{tabular}{|c|c|c|c|c|c|c|c|c|c|c|c|c|}
\hline & & Tempe & erature & & & Precip & itation & & & Hum & idity & \\
\hline & Spring & Summer | & Autumn & Winter & Spring | & Summer | & Autumn & Winter & Spring & Summer | & Autumn & Winter \\
\hline Sporting equipment, games and toys & $.45 * \cdots$ & & $-.19^{*}$ & & & & & & & & & \\
\hline Textile, clothing and footwear & $.58 \%$ & & $-.31 \cdots$ & & $-.45 * *$ & $.24^{* *}$ & & & $-.40^{* *}$ & & & \\
\hline Textiles & & $-.29 * \cdots$ & $-.27 * *$ & & & $.34 \cdots$ & & $.28 *$ & & $.38 * \cdots$ & & \\
\hline Clothing & $.53^{*} \cdots$ & & $-.26 \cdots$ & $.22 * *$ & $-.45 \cdots$ & & & $.28 *$ & $-.37 * \cdots$ & & & \\
\hline Footwear and leather goods & $.51 * *$ & & $-.24^{* *}$ & $.23 * *$ & $-.38 * *$ & & & & $-.38 * *$ & & & \\
\hline Alcoholic drinks, other beverages & & $.32 * \cdots$ & $-.48 * \cdots$ & & $-.22^{*}$ & & & & $-.28 * *$ & $-.29 * *$ & & \\
\hline Cosmetics and toilet articles & & & $-.22 \cdots$ & & $-.19^{*}$ & $-.20^{* *}$ & $-.26 * *$ & $.20 *$ & $-.38 * \cdots$ & $-.21^{\circ}$ & & \\
\hline Medical and orthopaedic goods & & & & & & & & & & & & $-.36 * \cdots$ \\
\hline Carpets, rugs, wall and floor coverings & $-.19^{*}$ & & & & & & & & & $.30 * \cdots$ & & \\
\hline Books, newspapers and stationery & & $-.33 * *$ & & & & & & & $.20 * \cdots$ & $.27^{* *}$ & & \\
\hline Audio, music and video recordings & & $-.19^{*}$ & & & $.23^{* *}$ & $.38 * \cdots$ & & & & $.28^{* *}$ & & \\
\hline Household goods & & $-.32 * \cdots$ & $.26^{*}$ & $.28 *$ & & $.46 * \cdots$ & & $.24^{* *}$ & & $.29 * \cdots$ & $.24^{* *}$ & \\
\hline Hardware, paints and glass & $.49^{* * *}$ & & $.24 * *$ & $.27^{* *}$ & $-.47 \cdots$ & & $-.27^{* *}$ & $.23^{* *}$ & $-.36 * *$ & & $.23 * *$ & \\
\hline Furniture, lighting and household articles & $-.20^{*}$ & $-.45 * *$ & $.33 * \cdots$ & $.33 *$ & $.28^{*} \cdot$ & $.48 * \cdots$ & & $.27 \cdot *$ & & $.42 * \cdots$ & $.33 *$ & \\
\hline
\end{tabular}

Table 2: Extraction of correlations for selected retail categories

\begin{tabular}{lcc} 
Sector & Season & Temp $_{m}$ \\
\hline Footwear & Spring & $\mathbf{3 . 2 3 8}^{\text {*** }}$ \\
Footwear & Autumn & $\mathbf{- 3 . 0 6 7}^{\text {*** }}$ \\
\hline Clothing & Spring & $\mathbf{1 . 6 4 8}^{* * *}$ \\
Clothing & Autumn & $\mathbf{- 1 . 1 3 3}^{* * *}$
\end{tabular}

Table 3: Wash-out effects in the case of footwear and clothing sales

\begin{tabular}{lccccccc} 
Sector & Season & $\Delta S_{m-1}$ & Temp & $\mathrm{c}$ & GDP & DW & Sargan \\
\hline Books & Summer & $0.391^{* * *}$ & $-3.159^{* * *}$ & 0.152 & & 2.102 & $6.068^{*}$ \\
Books & Summer & $0.323^{* * *}$ & $-3.003^{* * *}$ & $0.324^{* *}$ & $-14.075^{* * *}$ & 1.930 & $8.481^{*}$ \\
\hline Furniture & Summer & $0.397^{* * *}$ & $-2.424^{* * *}$ & 0.084 & & 2.058 & $15.760^{* * *}$ \\
Furniture & Summer & $0.271^{* * *}$ & $-1.939^{* * *}$ & $-0.936^{* * *}$ & $20.110^{* * *}$ & 1.756 & $13.705^{* *}$ \\
\hline Household goods & Summer & $0.380^{* * *}$ & $-1.276^{* * *}$ & 0.120 & & 1.8107 & $15.036^{* * *}$ \\
Household goods & Summer & $0.176^{* *}$ & $-1.142^{* * *}$ & $-0.653^{* * *}$ & $14.039^{* * *}$ & 1.469 & $14.433^{* * *}$ \\
\hline Textiles & Summer & $0.241^{* * *}$ & $-4.941^{* * *}$ & $0.640^{* * *}$ & & 1.779 & $15.895^{* * *}$ \\
Textiles & Summer & $0.274^{* * *}$ & $-4.361^{* * *}$ & $0.706^{* * *}$ & 2.637 & 1.818 & $16.069^{* * *}$ \\
\hline Alcoholic drinks & Autumn & $0.067^{* * *}$ & $11.445^{* * *}$ & $2.433^{* * *}$ & & 1.600 & $13.421^{* * *}$ \\
Alcoholic drinks & Autumn & $0.041^{* * *}$ & $11.697^{* * *}$ & $3.029^{* * *}$ & $-26.761^{* * *}$ & 1.625 & $13.793^{* *}$ \\
\hline Footwear & Autumn & 0.077 & $-1.052^{* * *}$ & -0.111 & & 1.453 & $8.909^{* *}$ \\
Footwear & Autumn & $0.228^{* * *}$ & $-0.977^{* * *}$ & $-0.539^{* * *}$ & $7.758^{* * *}$ & 1.783 & $14.687^{* * *}$ \\
\hline Hardware & Winter & -0.028 & $0.767^{* * *}$ & $0.765^{* * *}$ & & 1.492 & $13.094^{* * *}$ \\
Hardware & Winter & $0.047^{* * *}$ & $1.057^{* * *}$ & $1.407^{* * *}$ & $-15.869^{* * *}$ & 1.581 & $13.979^{* *}$
\end{tabular}

Table 4: Extraction of models for which Temperature is an influential variable 


\begin{tabular}{lccccccc} 
Sector & Season & $\Delta S_{m-1}$ & Precip $m$ & $\mathrm{c}$ & GDP & DW & Sargan \\
\hline Furniture & Summer & $0.421^{* * *}$ & $0.079^{* * *}$ & 0.168 & & 1.776 & $12.889^{* * *}$ \\
Furniture & Summer & $0.322^{* * *}$ & $0.054^{* * *}$ & $-0.675^{* * *}$ & $14.288^{* * *}$ & 1.643 & $13.722^{* * *}$ \\
\hline Cosmetics & Summer & $0.186^{* *}$ & $-0.0385^{* * *}$ & 0.122 & & 3.744 & $14.352^{* * *}$ \\
Cosmetics & Summer & $0.227^{* *}$ & $-0.040^{* * *}$ & $-0.253^{*}$ & $6.475^{* * *}$ & 1.824 & $13.149^{* *}$ \\
\hline Textiles & Summer & $0.259^{* * *}$ & $0.189^{* * *}$ & $0.785^{* * *}$ & & 1.600 & $11.254^{* *}$ \\
Textiles & Summer & $0.284^{* * *}$ & $0.184^{* * *}$ & $1.382^{* * *}$ & $-15.133^{* * *}$ & 1.649 & $11.008^{* *}$ \\
\hline Textiles & Winter & $0.626^{* * *}$ & $0.153^{* * *}$ & $0.428^{* * *}$ & & 2.417 & $13.362^{* * *}$ \\
Textiles & Winter & $0.506^{* * *}$ & $0.083^{* * *}$ & $2.909^{* * *}$ & $-39.048^{* * *}$ & 2.291 & $14.082^{* * *}$
\end{tabular}

Table 5: Extraction of models for which Precipitation is an influential variable

\begin{tabular}{lccccccc} 
Sector & Season & $\Delta S_{m-1}$ & $H r_{m}$ & c & GDP & DW & Sargan \\
\hline Medical & Winter & $0.420^{* * *}$ & $-1.162^{* * *}$ & $0.642^{* * *}$ & & 2.170 & $11.441^{* * *}$ \\
Medical & Winter & $0.374^{* * *}$ & $-1.437^{* * *}$ & $1.354^{* * *}$ & $-22.500^{* * *}$ & 2.075 & $12.363^{* *}$
\end{tabular}

Table 6: Extraction of models for which Humidity Rate is an influential variable

\begin{tabular}{lcccc} 
& Spring & Summer & Autumn & Winter \\
\hline Maximum positive deviation & $3.04^{\circ} \mathrm{C}$ & $1.67^{\circ} \mathrm{C}$ & $2.45^{\circ} \mathrm{C}$ & $2.17^{\circ} \mathrm{C}$ \\
Maximum negative deviation & $-2.11^{\circ} \mathrm{C}$ & $-1.89^{\circ} \mathrm{C}$ & $-2.57^{\circ} \mathrm{C}$ & $-3.02^{\circ} \mathrm{C}$ \\
Average deviation & $0.47^{\circ} \mathrm{C}$ & $0.37^{\circ} \mathrm{C}$ & $0.47^{\circ} \mathrm{C}$ & $0.57^{\circ} \mathrm{C}$
\end{tabular}

Table 7: 30 year statistics of UK abnormal temperatures 


\begin{tabular}{|c|c|c|c|c|c|c|c|}
\hline Weather & No hedge & Option & Net Cash-Flow & Collar & Net Cash-Flow & Swap & Net Cash-Flow \\
\hline 1986 & 300298 & - & 300298 & - & 300298 & -260241 & 40058 \\
\hline 1987 & -182532 & - & -182532 & - & -182532 & 222589 & 40058 \\
\hline 1988 & -190028 & - & -190028 & - & -190028 & 230085 & 40058 \\
\hline 1989 & 1287402 & - & 1287402 & -87402 & 1200000 & - 1247344 & 40058 \\
\hline 1990 & -542060 & - & -542060 & - & -542060 & 582118 & 40058 \\
\hline 1991 & -259383 & - & -259383 & - & -259383 & 299441 & 40058 \\
\hline 1992 & -1233243 & 233243 & -1000000 & 233243 & -1000000 & 1273300 & 40058 \\
\hline 1993 & -994460 & - & - 994460 & - & - 994460 & 1034517 & 40058 \\
\hline 1994 & 2604134 & - & 2604134 & - 1404134 & 1200000 & -2564077 & 40058 \\
\hline 1995 & 460248 & - & 460248 & - & 460248 & -420190 & 40058 \\
\hline 1996 & -1331449 & 331449 & -1000000 & 331449 & -1000000 & 1371506 & 40058 \\
\hline 1997 & 776381 & - & 776381 & - & 776381 & -736323 & 40058 \\
\hline 1998 & -930449 & - & - 930449 & - & - 930449 & 970507 & 40058 \\
\hline 1999 & 1257773 & - & 1257773 & -57773 & 1200000 & - 1217715 & 40058 \\
\hline 2000 & -854279 & - & -854279 & - & -854279 & 894337 & 40058 \\
\hline 2001 & 729245 & - & 729245 & - & 729245 & - 689187 & 40058 \\
\hline 2002 & -441920 & - & - 441920 & - & -441920 & 481977 & 40058 \\
\hline 2003 & -439863 & - & -439863 & - & - 439863 & 479920 & 40058 \\
\hline 2004 & 422395 & - & 422395 & - & 422395 & -382337 & 40058 \\
\hline 2005 & 270015 & - & 270015 & - & 270015 & -229957 & 40058 \\
\hline 2006 & 1321193 & - & 1321193 & - 121193 & 1200000 & - 1281136 & 40058 \\
\hline 2007 & -2077200 & 1077200 & -1000000 & 1077200 & -1000000 & 2117258 & 40058 \\
\hline 2008 & -862910 & - & - 862910 & - & -862910 & 902967 & 40058 \\
\hline 2009 & 1529291 & - & 1529291 & - 329291 & 1200000 & - 1489233 & 40058 \\
\hline 2010 & $\begin{array}{lll}-1 & 825 & 129\end{array}$ & 825129 & -1000000 & 825129 & -1000000 & 1865187 & 40058 \\
\hline 2011 & 2800100 & - & 2800100 & -1600100 & 1200000 & - 2760043 & 40058 \\
\hline 2012 & -2946624 & 1946624 & -1000000 & 1946624 & -1000000 & 2986681 & 40058 \\
\hline 2013 & 1127970 & - & 1127970 & - & 1127970 & - 1087912 & 40058 \\
\hline 2014 & 1384756 & - & 1384756 & - 184756 & 1200000 & -1344698 & 40058 \\
\hline Burn & & 152195 & & 21690 & & 69 & 40058 \\
\hline Std. Dev. & 1343604 & 427746 & 1116449 & 611827 & 887981 & & 0 \\
\hline
\end{tabular}

Table 8: Reconstructed net cash flows due to abnormal weather (in £); Maximum loss in margin in bold

\begin{tabular}{lcccc} 
& No Hedge & Option & Collar & Swap \\
\hline Max. loss on margin cash flow (\% of margin) & $-29.47 \%$ & $-10.00 \%$ & $-10.00 \%$ & $0.00 \%$ \\
Std dev on margin cash flow (\% of margin) & $13.44 \%$ & $11.16 \%$ & $8.88 \%$ & $0.00 \%$ \\
Cost of hedging (\% of margin) & - & $1.95 \%$ & $0.83 \%$ & $0.00 \%$ \\
Cost of hedging (\% of sales) & - & $0.19 \%$ & $0.08 \%$ & $0.00 \%$ \\
\hline
\end{tabular}

Table 9: Efficiency of weather hedging in reducing maximum loss and cash-flow uncertainty 


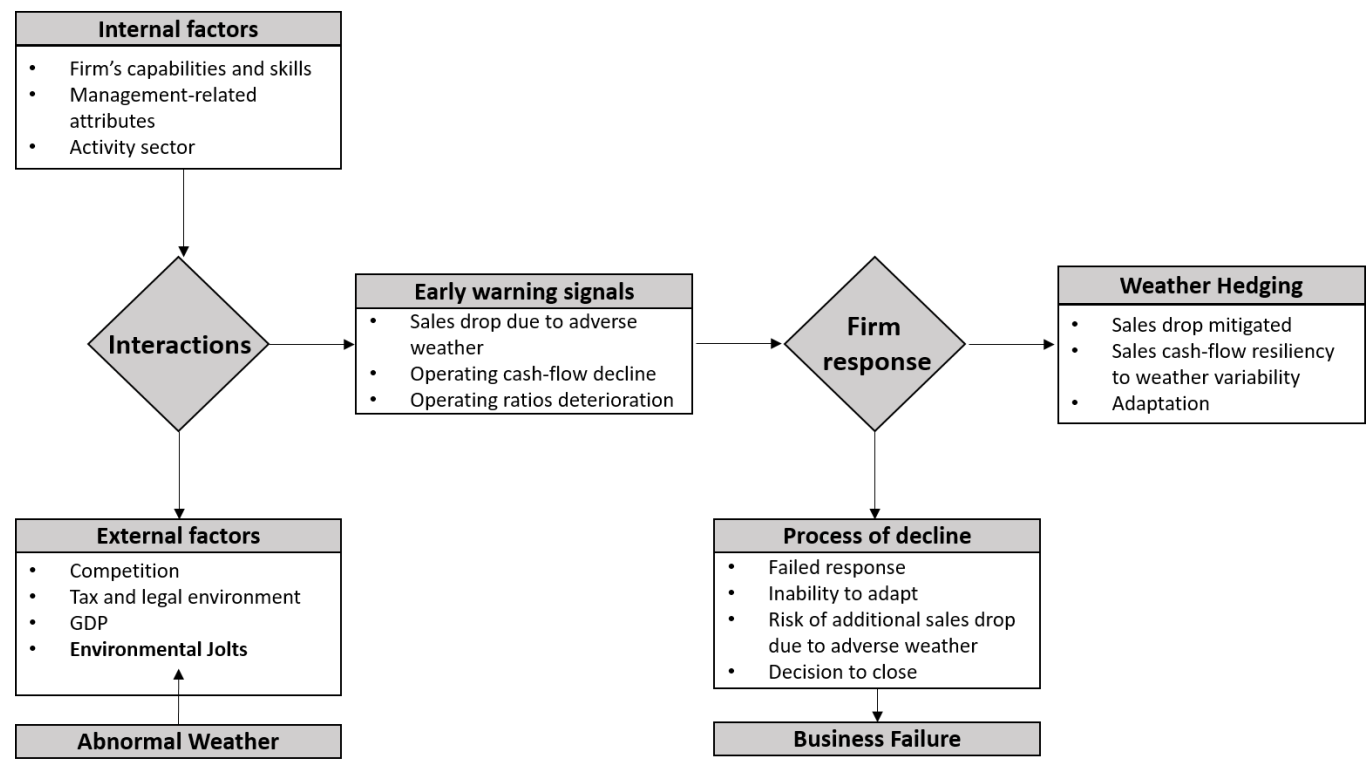

Figure 1: Integrative process framework of business failure (adapted from ?, and enclosed references) 


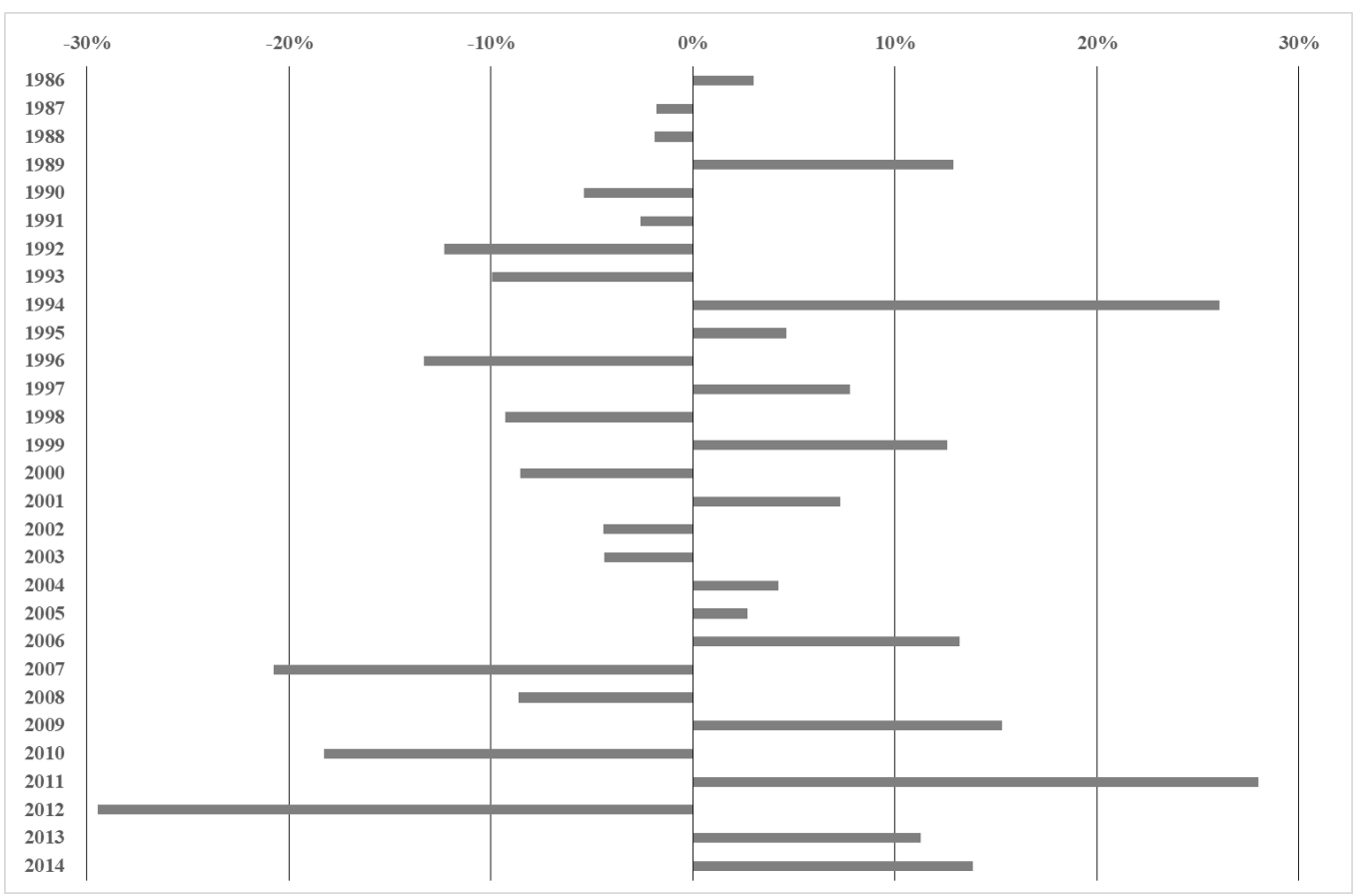

Figure 2: Reconstruction of the contribution of weather conditions observed over the last 30 years (\% of sales) 


\section{Appendix A.}

\begin{tabular}{llccc} 
Region & Station & USAF & Pop. & Weight (\%) \\
\hline SouthEast & Odiham & 37610 & 8792626 & 13,7 \\
GreaterLondon & London & 37720 & 8416535 & 13,1 \\
NorthWest & Manchester & 33340 & 7103260 & 11,1 \\
NorthEast & Boulmer & 32400 & 2610481 & 4,1 \\
East & Wattisham & 35900 & 5954169 & 9,3 \\
West Midlands & Birmingham & 35900 & 5674712 & 8,9 \\
SouthWest & Plymouth & 38270 & 5377595 & 8,4 \\
Yorkshire and the Humber & Leeming & 32570 & 5337710 & 8,3 \\
East Midlands & Nottingham & 33540 & 4598729 & 7,2 \\
Scotland & Aberdeen & 30910 & 5327700 & 8,3 \\
Wales & Milford & 36040 & 3082412 & 4,8 \\
Northern Ireland & Belfast Aldergrove & 39170 & 1829725 & 2,9 \\
\hline Total & & 64105654 & 100 \\
\hline
\end{tabular}

Table A.10: weather stations and population weights

\begin{tabular}{lccccccc}
\hline Sector & $\Delta S_{m-1}$ & Temp & $\mathrm{c}$ & $\mathrm{GDP}$ & $\mathrm{SAR}(4)$ & $\mathrm{MA}(1)$ & Breush-Godfrey \\
\hline Carpets & $0.844^{* * *}$ & $2.422^{* * *}$ & 1.114 & 10.896 & $0.095^{*}$ & $-0.346^{* * *}$ & $23.46^{* * *}$ \\
Hardware & $0.796^{* * *}$ & $2.835^{* * *}$ & 0.937 & -7.364 & $0.124^{* *}$ & $-0.480^{* * *}$ & $46.063^{* * *}$ \\
Textiles & 0.439 & $0.873^{* * *}$ & -0.082 & 3.763 & $0.254^{* * *}$ & $-0.332^{* * *}$ & $33.294^{* * *}$ \\
Cosmetics & $0.691^{* * *}$ & $1.580^{* * *}$ & -0.391 & $12.118^{*}$ & $0.084^{* * *}$ & -0.257 & $70.574^{* * *}$ \\
Household goods & $0.791^{* * *}$ & $0.621^{*}$ & -0.244 & $12.151^{*}$ & $0.104^{* *}$ & $-0.569^{* * *}$ & $10.373^{* *}$ \\
Footwear & $0.583^{* * *}$ & $1.945^{* * *}$ & -0.137 & 2.815 & $0.129^{* * *}$ & $-0.275^{*}$ & $64.527^{* * *}$ \\
Clothing & 0.418 & $0.787^{* * *}$ & -0.0510 & 3.681 & $0.270^{* * *}$ & -0.317 & $19.613^{* * *}$ \\
\hline Sector & $\Delta S_{m-1}$ & $P r c p_{m}$ & $\mathrm{c}$ & $\mathrm{GDP}$ & $\mathrm{SAR}(4)$ & $\mathrm{MA}(1)$ & Breush-Godfrey \\
\hline Audio & $0.733^{* * *}$ & $0.061^{*}$ & -0.794 & $36.116^{* *}$ & $0.127^{* * *}$ & $-0.385^{* * *}$ & $11.496^{* * *}$ \\
Books & $0.789^{* * *}$ & $0.149^{* * *}$ & 1.723 & $-26.882^{*}$ & $0.093^{*}$ & $-0.479^{* * *}$ & $47.238^{* * *}$
\end{tabular}

Table A.11: SARMA Models: Extraction of Results for Temperature and Precipitation, (1989-2015) 


\begin{tabular}{|c|c|c|c|}
\hline & Temperature & Precipitation & Humidity \\
\hline \multicolumn{4}{|l|}{ Spring } \\
\hline Maximum positive deviation & 3.04 & 42.88 & 5.94 \\
\hline Maximum negative deviation & -2.11 & -29.89 & -3.99 \\
\hline Average positive deviation & 0.50 & 6.80 & 0.95 \\
\hline Average negative deviation & -0.43 & -7.10 & -0.93 \\
\hline $5 \%$ positive threshold & 2.28 & 32.30 & 4.92 \\
\hline $5 \%$ negative threshold & -1.36 & -28.00 & -3.44 \\
\hline \multicolumn{4}{|l|}{ Summer } \\
\hline Maximum positive deviation & 1.67 & 42.34 & 6.25 \\
\hline Maximum negative deviation & -1.89 & -54.69 & -8.36 \\
\hline Average positive deviation & 0.37 & 8.64 & 1.34 \\
\hline Average negative deviation & -0.36 & -9.28 & -1.45 \\
\hline $5 \%$ positive threshold & 1.52 & 36.60 & 5.65 \\
\hline $5 \%$ negative threshold & -1.37 & -28.90 & -6.37 \\
\hline \multicolumn{4}{|l|}{ Autumn } \\
\hline Maximum positive deviation & 2.45 & 60.18 & 3.43 \\
\hline Maximum negative deviation & -2.57 & -54.26 & -3.54 \\
\hline Average positive deviation & 0.46 & 10.25 & 0.73 \\
\hline Average negative deviation & -0.47 & -9.20 & -0.64 \\
\hline $5 \%$ positive threshold & 2.28 & 41.30 & 2.63 \\
\hline $5 \%$ negative threshold & -1.82 & -42.10 & -2.90 \\
\hline \multicolumn{4}{|l|}{ Winter } \\
\hline Maximum positive deviation & 2.17 & 50.35 & 3.99 \\
\hline Maximum negative deviation & -3.02 & -61.8 & -4.20 \\
\hline Average positive deviation & 0.59 & 10.35 & 0.69 \\
\hline Average negative deviation & -0.55 & -10.80 & -0.70 \\
\hline $5 \%$ positive threshold & 2.08 & 46.90 & 3.19 \\
\hline $5 \%$ negative threshold & -2.55 & -39.2 & -2.10 \\
\hline
\end{tabular}

Table A.12: Historical unseasonal weather Statistics 